\title{
O CADE COMO AGENTE REGULAMENTADOR
}

THE CADE AS A REGULATORY AGENT

Fabio Fernandes Neves BENFATTI ${ }^{1}$

Eduardo Augusto do Rosário CONTANI ${ }^{2}$

Flávia Alcântara Fogaça Babora MAZZARI ${ }^{3}$

ISSUE DOI: 10.21207/1983.4225.v15.n1.2020.863

\section{RESUMO}

Na relação Capital e Trabalho, um dos fatores é o acúmulo individual de capital e a exploração do Trabalhador; e esse capital, passa a ter a tendência de se auto reproduzir, multiplicar-se. Daí a necessidade de uma política estatal voltada para a limitação da exploração do trabalho. Isso ocorre porque o Sistema Capitalista de produção é produtor de crises.

\footnotetext{
${ }^{1}$ Professor Efetivo de Direiro Civil da Universidade do Estado de Minas Gerais (UEMG), Frutal/MG. Pós Doutor pela Università degli Studi di Messina, Itália. Doutor em Direito Político e Econômico pela Universidade Presbiteriana Mackenzie (UPM). Graduação em Direito e Mestrado em Direito Negocial, ambos pela Universidade Estadual de Londrina (UEL). Currículo Lattes: http://lattes.cnpq.br/5196720969148247. Contato: fabio.neves@uemg.br.

${ }^{2}$. Doutor e Mestre em Administração com ênfase em Finanças pela Universidade de São Paulo (2014), Especialista em Administração (FGV-EAESP, 2006) e Bacharel em Engenharia Mecânica pela Universidade de São Paulo (2004). Atualmente é Professor da Universidade Estadual de Londrina (UEL), das Faculdades Integradas do Vale do Ivaí - Univale Ivaiporã e das Faculdades Londrina. É coordenador do curso de Administração das Faculdades Londrina. Foi Visiting Scholar na Universidade de Columbia (EUA) em 2011 e 2012. Currículo Lattes: http://lattes.cnpq.br/9581308995467871. Contato: eduardocontani@gmail.com.

${ }^{3}$ Possui graduação em Direito pela Faculdade Pitágoras de Londrina(2012). Tem experiência na área de Direito, com ênfase em Direito Privado. Currículo Lattes: http://lattes.cnpq.br/7583160398734080. Contato: flavia.babora@hotmail.com.
} 
Palavras-chave: Direito; CADE; Secretaria de Direito Econômico; Direito Concorrencial.

\begin{abstract}
In the Capital and Labor relationship, one factor is the individual capital accumulation and exploitation of the Worker; and this capital, has the tendency to reproduce itself, to multiply. Hence the need for a state policy aimed at limiting the exploitation of labor. This is because the Capitalist System of production is a producer of crises.
\end{abstract}

Keywords: Right; CADE; Secretariat of Economic Law; Competition Law.

\title{
$1 \quad$ ANTECEDENTES
}

Na relação Capital e Trabalho, um dos fatores é o acúmulo individual de capital e a exploração do Trabalhador; e esse capital, passa a ter a tendência de se auto reproduzir, multiplicar-se. Daí a necessidade de uma política estatal voltada para a limitação da exploração do trabalho. Isso ocorre porque o Sistema Capitalista de produção é produtor de crises,

Entretanto, com a crise econômica mundial que teve início com os subprimes e instituições financeiras nos EUA, ganhou destaque um outro G-20, disposto a analisar o mundo diante da crise e buscar alternativas para reverter tal cenário e desenvolver a economia global, tratando de temas como retomada do crescimento econômico, ajuda aos países em desenvolvimento, condenação do protecionismo, reforma e regulação do sistema financeiro, financiamento do comércio exterior e reforma do FMI. ${ }^{4}$

E prossegue para relatar também a ideologia como forma de dominação da ordem jurídico-político-econômica.

\begin{abstract}
Assim, entende-se que a ordem jurídico-político-econômica enquanto conjunto legal infraconstitucional é a política econômica posta em prática, ao passo que a conjunção da ordem jurídicoeconômica elaborada na esfera de uma ordem política que reflete seu momento histórico significa a ideologia adotada para aquela política econômica. ${ }^{5}$
\end{abstract}

Dessa maneira, aponta Fonseca:

\footnotetext{
${ }^{4}$ Bagnoli , Vicente. Direito econômico, $6^{a}$ edição. Atlas, 2013. p. 262.

${ }^{5}$ Bagnoli, ob. cit. p. 27.
} 
A concentração econômica gerou problemas no relacionamento Econômico e social dentro do mercado, o que exigiu que uma nova força entrasse em cena. A concentração econômica fez surgir o poder Econômico privado que, de um lado, procurou dominar e eliminar as empresas economicamente mais fracas, e, de outro lado, gerou uma situação de violenta dominação sobre os trabalhadores, que Marx e Engels detectaram no meado do século. ${ }^{6}$

Este momento bem delineado historicamente demonstra a necessidade de um intervencionismo estatal e da busca de um Estado Social $^{7}$, onde as tensões sociais fossem controladas pela busca de um mito social, com a cessão de alguns direitos. Esse processo nem sempre ocorre com eficácia plena, e essas tensões sociais apresentadas como luta de classes, no sentido marxista do termo, podem, no entender de Grau, converter-se no mito social Constitucional. ${ }^{8}$

Para esse autor, "O conceito de ordem econômica, se é de ordem econômica constitucional que cogitamos - e, de fato, é, - é bastante próximo, do conceito de Constituição Econômica." 9

A função da Constituição Econômica é limitar o Poder Privado Econômico, condicionar a atuação dos poderes econômicos privado, organizar o Estado, implementar políticas públicas, nesse sentido Ana Paula Dallari Bucci:

(...) A percepção desse processo será cada vez mais visível enquanto se mantiver o consumo acelerado dos recursos da terra, que aumenta continuamente, chegando a varias vezes a capacidade do planeta, o que só é possível porque ele se distribui de maneira desigual, apresentando excesso no mundo ocidental desenvolvido - paradigma reivindicado por alguns países em desenvolvimento e carência nos outros, como os países africanos, por exemplo, que jamais retirarão suas cotas nesse 'fundo ambiental' do planeta. Por essa razão, definindo-se o desenvolvimento, do ponto de vista das pessoas, como questão de liberdade, resta enfrentar as estruturas econômicas, sociais e politicas que historicamente se associam à produção e reprodução da desigualdade, da pobreza e do

6 FONSECA, João Bosco. Direito econômico. 5. ed., Rio de Janeiro: Forense, Rio de Janeiro, 2004. p. 16.

${ }^{7}$ Bagnoli, ob. cit. "Na Alemanha, os efeitos da Crise de 1929 também eclodiram. Nesse ano, a força motriz do capital organizado, o empresariado, declara seu descontentamento com o modelo da República de Weimar, em meio à crise econômica, e passa a combater o aumento de salários, as garantias dos trabalhadores e, sobretudo, o Estado Social." p. 17

8 GRAU, Eros Roberto. A ordem econômica na constituição de 1988. 8. ed., São Paulo: Malheiros, 2003 op. cit. p. 24-27, nessa linha de raciocínio são míticas as constituições de Weimar de 1919 e Mexicana de 1917, pois atribuíram ao legislador infraconstitucional a função de regulamentar a Constituição.

GRAU, op. cit. p. 59 
subdesenvolvimento. (...) as organizações estatais buscarão também limitar o poder destrutivo do capital. ${ }^{10}$

O estudo das forças sociais e a sua relação com as agências reguladoras em especial o CADE, desse questionamento surgem questões de estudo de cunho teórico e prático, com construção de uma sociedade livre, justa e solidária, erradicando a pobreza e as desigualdades sociais e regionais. Desta forma, o objetivo principal deste trabalho é destacar o papel regulador e interventor do CADE e seus efeitos no desenvolvimento econômico brasileiro.

\section{PANORAMA ECONÔMICO}

No início deste século, o mundo experimentou um crescimento econômico contínuo até o final dos anos 2000. Dentre os fatores que podem explicar o crescimento no início deste século foram o incremento de produtividade, mudanças demográficas e os novos negócios originados. Lipset (1959) argumenta o desenvolvimento econômico e a legitimidade política são requisitos sociais da democracia.

Reflete Konder Comparato que

É em função desse objetivo último de realização de justiça social que devem ser compreendidos e harmonizados os demais princípios expressos no art. 170, a par da livre concorrência, a saber especificamente, a função social da propriedade, da defesa do consumidor, a redução das desigualdades regionais e sociais, a busca do pleno emprego e o tratamento favorecido para as pequenas empresas brasileiras de capital nacional de pequeno porte. ${ }^{11}$

É necessária uma postura científica de distanciamento do pesquisador, a tal ponto que o torne imparcial para se analisar toda o completude do Desenvolvimento Econômico. O que para Furtado traz outra questão à tona,

[...] que tampouco é possível ignorar as diferenças de estrutura entre economias de graus distintos de Desenvolvimento. Como as relações referidas pressupõem certa estabilidade estrutural, o

\footnotetext{
${ }^{10}$ BUCCI, Maria Paula Dallari. Fundamentos para uma Teoria Jurídica das Politicas Publicas, São Paulo, Saraiva, 2013. op. cit. Pag. 95

${ }^{11}$ COMPARATO. Fábio Konder Regime Constitucional de Controle de Preços no Mercado. Direito Público, 97/17 p. 19
} 
problema que se nos apresenta é duplo: primeiro saber até que ponto é possível generalizar para outras estruturas observações feitas em uma; segundo, definir relações que sejam suficientemente gerais para terem validez no curso de determinas modificações estruturais. Que valor explicativo poderão ter, observações feitas em um modelo suficientemente geral para satisfazer essas ressalvas? O rigor da analise econômica consiste exatamente em definir os limites dessa validez. O esforço no sentido de alcançar níveis mais altos de abstração deve ser acompanhado de outro objetivando definir, em função de realidades históricas, os limites de validade das relações inferidas. A complexidade da ciência econômica - seu caráter abstrato e histórico - aparece, assim, em toda a plenitude na teoria do Desenvolvimento Econômico. ${ }^{12}$

\section{A questão é, assim, identificar Desenvolvimento Econômico de maneira científica, aplicando esquemas explicativos à realidade observada sem perder de vista o seu caráter histórico, assim Bercovici}

O Estado, assim, se torna um campo de conflitualidade permanente, ao abranger novos setores e atores antes excluídos pelo liberalismo, tornando-se um local de alianças e compromissos. (...) Nesse contexto de ebulição social, a manifestação a manifestação do poder constituinte não vai poder ser bloqueada e o resultado será uma alteração profunda nas estruturas constitucionais e estatais. ${ }^{13}$

\section{Permitindo compreender o cenário do Desenvolvimento Econômico sem dissociá-lo do que efetivamente ocorre em diferentes estágios apreendidos historicamente e aferir se de fato ocorre Crescimento ou Desenvolvimento. Como enfatiza Furtado:}

A questão da natureza abstrata ou histórica do método com que
trabalha o economista não é independente, destarte, dos problemas
que o preocupam. O Desenvolvimento Econômico é um fenômeno
com nítida dimensão histórica. Cada economia que se desenvolve
enfrenta uma série de problemas que lhe são específicos, se bem
que muitos deles sejam comuns a outras economias
contemporâneas. O complexo de recursos naturais, as correntes
migratórias, a ordem institucional, o grau relativo de
Desenvolvimento das economias contemporâneas singularizam
cada fenômeno histórico de Desenvolvimento. Tomemos ao acaso
um exemplo: Cuba pré-revolucionária. Poucas economias terão se
desenvolvido com maior rapidez do que a desse pais, graças a uma
integração crescente no comércio internacional. Também poucas

${ }^{12}$ FURTADO, Celso. Teoria e política do desenvolvimento econômico. 10. ed. São Paulo: Paz e Terra, 2000, p. 16.

${ }^{13}$ BERCOVICI, Gilberto. Soberania e Constituição. Para uma critica do Constitucionalismo. Quartier Latin. São Paulo, 2008, pag. 290 e 294. 
economias encontrariam, posteriormente, maiores dificuldades para sair da estagnação, devido à natureza de suas relações de intercâmbio externo. O comércio exterior ai aparece, portanto, como um fator estimulante e impeditivo do Desenvolvimento. ${ }^{14}$

O conteúdo histórico é único e remetido a uma realidade onde ocorre a análise, o que exige a conjugação dos fatores tempo e espaço na compreensão do Desenvolvimento. O Desenvolvimento Econômico não é uniforme, com uma regra geral porque cada país possui a sua especificidade. Ainda segundo Furtado,

Definindo-se produtividade social como produto por unidade de tempo de ocupação do conjunto da força de trabalho de uma coletividade, deduz-se que a teoria do Desenvolvimento inclui, necessariamente, uma teoria macroeconômica da produção. É por esta via que os teóricos da economia se preocuparam com a temática do Desenvolvimento. O que se pode esperar de uma teoria de produção? Que nos descreva como, historicamente, se vem realizando o processo de produção; que nos exponha o mecanismo do processo de produção e as relações funcionais e de causalidade entre as variáveis pertinentes; que nos mostre as relações entre o crescimento da produção e a forma de distribuição da renda, e entre as modificações desta ultima e o ritmo de acumulação; finalmente, que nos diga qual a taxa máxima virtual de acumulação e em que condições pode ser alcançada. ${ }^{15}$

\section{Entende Grau que}

É desde essas verificações que se haveria de orientar a política de privatização das empresas estatais. A política neoliberal também nessa matéria implementada pelo governo Fernando Henrique é incompatível com os fundamentos do Brasil, afirmados no art. $3^{\circ}$ da Constituição de 1988, e com norma veiculada pelo seu art. 170. ${ }^{16}$

Mesmo na Democracia participativa é discutível a legitimidade para atuações administrativas, ainda que convenientes e oportunas. A oxigenação pela alternância de poder político é perfeitamente saudável para a sociedade, no entanto, o exercício de um mandato fruto do sufrágio direto não é autorização para atuação governamental que contradiga a Constituição Federal ou mesmo a Soberania Popular

O Poder Constituinte seria real, para Friedrich Muller, se os poderes constituídos fossem exercidos pelo próprio constituinte. $\mathrm{O}$

\footnotetext{
${ }^{14}$ FURTADO, op. cit, p. 18.

${ }^{15}$ Ibid, p. 19-20.

${ }^{16}$ GRAU, Ob. cit. p. 36
} 
Estado constitucional, no entanto, é contrario a isso. O povo utiliza o seu poder para fundar os outros poderes que, a partir de sua criação, passam a dispor sobre o povo. Não há poder constituinte onde o povo é alienado do poder. ${ }^{17}$

Assim é que para Streck (2004) “A argüição de descumprimento de preceito fundamental, o mandado de injunção, a inconstitucionalidade por omissão, e tantos outros dispositivos previstos na nova Constituição continuem ineficazes. [...] Enfim, continuamos a olhar o novo com os olhos do velho $[. . .]^{\prime 18}$ o que na visão ainda de Streck, é típico de Democracias tardias e arcaicas.

No Brasil a modernidade é tardia e arcaica. (...) de cunho autopoiético. [...] um monumento à negligência social, onde a pósmodernidade é vista com uma visão neoliberal. O imenso déficit social [...] em países como o Brasil, onde o Estado Social não existiu, o agente principal de toda política social deve ser o Estado, [...] é razoável afirmar que o Direito, por ter uma Constituição democrática, deve ser visto, hoje, como um campo necessário de luta para implantação das promessas modernas, $[. .$.$] há até mesmo$ uma crise de legalidade, uma vez que nem sequer é cumprida, frente a inefetividade dos dispositivos da Constituição. ${ }^{19}$

A crise do Poder Judiciário e a crise do Estado, passam a demonstrar a fragilização do sistema jurídico, pois "a fragilização do Poder Judiciário atende a interesses bem marcados de Executivos fortes." ${ }^{20}$, nesse sentido também Maria Paula Dallari Bucci.

A Constitucionalização da economia e do planejamento tem um significado especifico para as 'democracias tardias'. O estabelecimento da democracia de um Estado emergente é um fator a mais a exigir e inspirar a criatividade jurídico-institucional para a diversificação das abordagens estatais. ${ }^{21}$

\section{Como bem compreende Grau,}

A Constituição formal, em especial enquanto concebida como meramente programática - continente de normas que não são normas jurídicas, na medida em que define direitos que não garante, na medida que esses direitos só assumem eficácia plena quando

\footnotetext{
${ }^{17}$ BERCOVICI, Ob. cit p. 37.

${ }^{18}$ STRECK, Lênio Luiz, Jurisdição constitucional e hermenêutica: uma nova crítica do direito. 2. ed., revista e ampliada. Rio de Janeiro: Forense, 2004. p. 17

19 STRECK, Lenio Luiz. Hermenêutica Jurídica e(m) crise: uma exploração hermenêutica da construção do Direito. 5. ed., Livraria do Advogado, 2004, p. 23 passin 27.

${ }^{20}$ STRECK, Ob. cit. p. 1.

${ }^{21}$ BUCCI, Ob. cit. Pag. 94
} 
implementados pelo legislador ordinário ou por ato do Executivo , consubstancia um instrumento retórico de dominação. Porque esse o perfil, ela se transforma em mito. ${ }^{22}$

\section{Grau assinala que}

A legalidade ainda por outro lado, enquanto garantidora das liberdades do individuo (liberdades formais), prospera não apenas no sentido de prover a sua defesa contra o arbítrio do Estado, mas instrumenta também a defesa de cada individuo titular da propriedade contra a ação dos não proprietários.

Sobre tais pressupostos é erigida o Estado Burguês de Direito, ao qual incumbe tutelar as instituições básicas do comercio jurídico burguês, especialmente o contrato e a propriedade. ${ }^{23}$

Para evitar-se a mitificação constitucional é necessário que se tenha coragem para aplicá-la, devendo portanto haver formas efetivas de sua realização, entendendo como sendo direito mínimo a ser aplicado, sendo o Constitucionalismo a limitação da própria soberania popular no entender de Gilberto Bercovici ${ }^{24}$.

Pondera Grau que

A substituição do modelo de economia de bem estar consagrado na Constituição de 1988 por outro, neoliberal, não poderá ser efetivada sem previa alteração dos preceitos contidos nos seus arts. $1^{\circ}, 3^{\circ}$ e 170 . Em outros termos: essa substituição não pode ser operada sub-repticiamente, como se os nossos governantes pretendessem ocultara o seu comprometimento com a ideologia neoliberal..$^{25}$

\section{Ainda com relação à teoria do estado estacionário, já na fase industrial verifica-se a continuidade da luta de classes, e, segundo Furtado,}

[...] economistas da classe industrial inglesa no calor da luta contra os proprietários da terra e contra a classe operária que começava a organizar-se, J. S. Mill formulou sua célere 'teoria geral do progresso Econômico', que, na verdade, é uma teoria da tendência ao estado estacionário.[...]. O progresso técnico seria, destarte, o meio de defesa da classe capitalista contra a elevação dos salários.

\footnotetext{
${ }^{22}$ GRAU, Ob. cit. p. 118

${ }^{23}$ GRAU, Ob. cit., p. 119.

${ }^{24}$ BERCOVICI, ob. cit nesse sentido pag. 158 e seguintes.

${ }^{25}$ GRAU, op. cit. p. 37
} 
Mas a elevação dos salários não beneficiaria os operários, e sim aqueles que auferiam a renda da terra. ${ }^{26}$

Essas observações evidenciam as contradições entre proprietários - ainda em estágio incipiente nesse período, o que facilita sua visualização -, as quais com o passar do tempo ficariam mais veladas, nesse sentido Octaviani escreve:

Parte central desse modelo é 'a blindagem da Constituição Financeira e a agonia da Constituição Economica', operada, no Brasil, pela 'consolidação da supremacia do orçamento monetário, ou seja, a garantia do custo da moeda (...), voltado para a estabilidade monetária, sobre o orçamento fiscal. A ordem econômica intervencionista e dirigente da Constituição de 1988 é isolada de seus instrumentos financeiros, cuja efetividade é medida em si mesma, sem qualquer relação com os objetivos da politica econômica estatal ou da ordem econômica constitucional. A Lei de Responsabilidade Fiscal e a insana proposta de emenda constitucional instituindo o defict nominal zero são meios de excluir o orçamento de deliberação publica, garantindo metas de politica monetária muitas vezes impostas de fora e em favor de interesses econômicos privados, que desejam uma garantia sem risco para seus investimentos ou para sua especulação financeira. A implementação da ordem econômica e da ordem social da Constituição de 1988 ficaram restritas, assim, as sobras orçamentarias e financeiras do Estado. ${ }^{27}$

Há de se destacar no cenário de desenvolvimento econômico, o papel da intervenção ou regulação no incremento de investimentos por parte das empresas. Motta, Funchal e Fortunato (2010, p. 9) identificam os impactos dos investimentos no desempenho das empresas brasileiras e encontram evidências de que o aumento dos investimentos também aumenta o valor das empresas. Incertezas políticas foram objeto de estudo de Julio e Yook (2011, p. 8-22), que verificaram o efeito das eleições e peculiaridades regionais nos investimentos de empresas de 48 países de diferentes setores. Os autores constataram uma queda média de 4,8\% nos investimentos em anos eleitorais em relação aos demais, levando a crer que as empresas reduzem investimentos devido a incertezas políticas.

O processo de Desenvolvimento da América Latina é ideológico e mítico, pois comporta um subdesenvolvimento econômico latente e estável, ou seja, são conquistas subdesenvolvimentistas, com o objetivo de

\footnotetext{
${ }^{26}$ FURTADO, Celso. Teoria e política do desenvolvimento econômico. 10. ed. São Paulo: Paz e Terra, 2000. p. 22

27 OCTAVIANI, Alessandro. RECURSOS GENETICOS E DESENVOLVIMENTO: OS DESAFIOS FURTADIANO E GRAMSCIANO, pag. 43 e 44.
} 


\title{
manter-se nesse estágio precário de Desenvolvimento, ou Desenvolvimento dependente. Isto porque, segundo Furtado,
}

\begin{abstract}
Os mitos têm exercido inegável influência sobre a mente dos homens que se empenham em compreender a realidade social. Do bon sauvage, com que sonhou Rosseau, à idéia milenária do desaparecimento do Estado, em Marx, do princípio populacional de Malthus à concepção walrasiana do equilíbrio geral, os cientistas sociais têm buscado apoio em algum postulado enraizado num sistema de valores que raramente chegam a explicitar. O mito congrega um conjunto de hipóteses que não podem ser testadas. Contudo, essa não é uma dificuldade maior, pois o trabalho analítico se realiza a um nível muito mais próximo à realidade. A função principal do mito é orientar, num plano intuitivo, a construção daquilo que Schmpeter chamou de visão do processo social, sem a qual o trabalho analítico não teria qualquer sentido. ${ }^{28}$
\end{abstract}

Por fim, se faz necessário a apreensão da riqueza energética, pela própria nação, assim Bercovici, afirma:

A recuperação do controle nacional sobre os recursos naturais, especialmente o petróleo e minérios, portanto, não é um desejo. É uma necessidade. A apropriação do excedente gerado pela exploração destes recursos, ampliados com as descobertas do présal, deve ser dirigida para o sentido emancipatório do artigo $3^{\circ}$ da Constituição de 1988. As alternativas são muito claras: ou este excedente contribuirá para manter o Brasil uma economia dependente e associada, a reboque das variações de preços do mercado internacional de produtos primários, consistindo o petróleo em mais um dos inúmeros ciclos econômicos vividos na historia do pais, mais um dos nossos 'milagres' para exportação, ou este excedente terá um papel decisivo no financiamento das politicas necessárias para a superação do subdesenvolvimento e, assim, completar a construção da Nação. ${ }^{29}$

Só assim será possível a implementação da inovação e a própria Soberania Plena, aquela que foi proposta pela própria Constituição Federal.

\section{O CADE COMO REGULADOR (OU) INTERVENTOR.}

\footnotetext{
${ }^{28}$ FURTADO. Ob. cit p. 15.

${ }^{29}$ BERCOVICI, Ob. cit.. 360 e 361.
} 
Nesse momento, oportuna a discussão entre a função do CADE, se regulamentador ou interventor, Del Masso entende como não sendo de regulamentação

No caso do CADE, a autarquia não possui funções de regulamentação da competição no Brasil, mas, ao impor obrigações aos agentes econômicos, seja na análise de condutas ou de estruturas de mercado, é patente a sua função regulatória, ainda que diferente das demais, pois não regula um setor econômico específico, mas sim a conduta das empresas em quaisquer mercados no que diz respeito à concorrência. ${ }^{30}$

\section{E complementa Bagnoli,}

Caso fosse juridicamente possível a efetiva intervenção do CADE no âmbito de atuação de outros órgãos de governo, melhor seria o termo "determinar" ao termo "recomendar", ou pelo menos que, na sua recomendação, o CADE indicasse o alcance ou os efeitos esperados da penalidade a ser aplicada, sem criar insegurança jurídica. ${ }^{31}$

E prossegue,

Por outro lado, uma importante inovação em relação à Lei 8.884/1994 está na alínea "a", do inciso IV, que trata de licença compulsória de direito de propriedade intelectual. A nova lei inseriu a parte final "quando a infração estiver relacionada ao uso desse direito", o que se mostra fundamental, visto que esta penalidade complementar somente poderá recair no caso da infração relacionar-se diretamente a algum direito de propriedade intelectual..$^{32}$

Contudo, sendo o CADE, autarquia Federal, como toda a Administração Publica, também será orientado pelos princípios da Administração Pública inscrita no artigo 37 da Constituição da República, em destaque o principio da razoabilidade, devendo existir uma verdadeira cautela para intervenção do CADE na economia. ${ }^{33}$

\footnotetext{
${ }^{30}$ MASSO, Fabiano Dolenc Del. Direito Econômico - Esquematizado. Método, 2012. p. 118

${ }^{31}$ BAGNOLI, Vicente. Comentários à Nova Lei de Defesa da Concorrência. Método, 2012. p. 173

${ }^{32}$ BAGNOLI, ob. cit. p. 173

${ }^{33}$ Nesse sentido, o voto do Ex-Conselheiro LUIZ CARLOS DELORME PRADO: "Embora justificada a importância dada na legislação brasileira ao controle de concentração, o artigo 54 da Lei 8.884/1994, pela sua generalidade, pode gerar grande insegurança jurídica. Em especial, o parágrafo terceiro abre espaço para que se justifique a comunicação de um grande número de atividades de cooperação econômica. Para que o Sistema Brasileiro de Concorrência não seja inundado com grande número de
} 
A possibilidade da aprovação parcial prevista no caput do artigo 61 é expressamente introduzida na Lei em clara consagração dos princípios da razoabilidade e proporcionalidade que informam a atividade administrativa e indicam que a intervenção do Estado na livre iniciativa não deve ir além do estritamente necessário para assegurar o interesse público. ${ }^{34}$

\begin{abstract}
Alguns estudos enfocam a visão do governo como órgão regulador e centralizador, como em Guedes e Gasparini (2007), ao analisarem a descentralização fiscal nos estados brasileiros. Costa et al (2009, p. 30-31), por exemplo, relatam os impactos regulatórios em alguns aspectos contábeis, enquadrando o conservadorismo de empresas brasileiras.
\end{abstract}

No campo da Intervenção, importante é a distinção proposta com Bagnoli.

Pode-se, ainda, colocar a intervenção direta do Estado na ordem econômica como a prestação de um serviço público, nos termos do art. 175 da Constituição, ou ainda como exploração da atividade econômica, observando o disposto nos arts. 173 e 177 da Constituição. De qualquer forma, seja serviço público, seja atividade econômica, trata-se do Estado diretamente exercendo uma atividade de natureza econômica. ${ }^{35}$

\title{
Prossegue ao dispor que a regulamentação seria uma das espécies de intervenção
}

(...) falhas de mercado são as situações em que os recursos, que são escassos, não são utilizados de maneira ótima, refletindo no preço e na qualidade de produtos e serviços. Nessas situações, a intervenção do Estado se justifica em defesa do bem-estar da sociedade, sobretudo por meio da regulação. ${ }^{36}$

\footnotetext{
Atos de Concentração, para os quais não há qualquer razão econômica que recomende sua submissão, é necessário que a jurisprudência do CADE estabeleça claramente uma interpretação do alcance desse texto jurídico. O ponto de partida para este análise é a premissa que a intervenção na iniciativa privada deve sempre ser feita de maneira cautelosa, resguardando-se o princípio de que a ação do Estado deve ser a menor possível compatível com a defesa dos direitos tutelados. O interesse público tutelado pelo CADE é a defesa da concorrência. Portanto, inexiste in- teresse público na submissão de uma operação que não possui as particularidades previstas pela Lei, visto que não tem capacidade de produzir qualquer efeito negativo no mercado". Voto do Conselheiro Relator Dr. Luiz Carlos Delorme Prado, no Ato de Concentração n.o 08012.002442/04-03, proferido em 15 de dezembro de 2004, de interesse das empresas Líder Táxi Aéreo S/A - Air Brasil e Helicópteros do Brasil S/A. In DOU de 9 de fevereiro de 2005, Seção 1, pág. 26.

${ }^{34}$ BAGNOLI, Vicente. Comentários à Nova Lei de Defesa da Concorrência. Método, 2012. p. 173

${ }^{35}$ BAGNOLI , Vicente. Direito econômico, $\sigma^{a}$ edição. Atlas, 2013. p. 107;

${ }^{36}$ Bagnoli , ob. cit. p. 115
} 
Sendo uma política importante de defesa sobretudo da concentração econômica, e até de defesa nacional, pois essas seriam geralmente sociedades empresárias internacionais.

Especificamente no campo econômico, diz respeito à redução da intervenção direta do Estado, que deixa de atuar diretamente nos mercados como agente econô- mico, e à concentração econômica, uma vez que no lugar do Estado os serviços passam a ser prestados por grupos econômicos, geralmente grandes e transnacionais. ${ }^{37}$

\section{Passa a ser assim um importante instrumento de bem estar social, no sentido de fomenta-lo ou reduzi-lo, dependendo da concepção de Estado Liberal ou de Bem Estar Social.}

(...) compreender a teoria da regulação econômica, importante verificar que, tradicionalmente, as escolas clássicas ocupam-se do estudo do funcionamento do Estado na economia, partindo de duas tradições. A primeira tradição considera que os reguladores possuem informação suficiente e força de coação para efetivamente promover o interesse público (public interest theories

Já a segunda tradição considera que os reguladores não possuem informações suficientes acerca do comportamento das empresas, de modo que apenas imperfeitamente e eventualmente conseguiriam promover o interesse público a partir do controle da atividade empresária, de modo que cada agente econômico atua conforme os seus interesses (private interest theories of regulation).

Em linhas gerais, para as teorias do interesse público a regulação aumenta o bem- -esstar social diante das falhas de mercado e pela intervenção governamental eficien- te. Já para as teorias do interesse privado a transferência de riquezas para grupos de interesses (grupos de pressão, que podem ser empresas, consumidores, reguladores, sindicatos, dentre outros) mais organizados pode reduzir o bem-estar social, de modo que dependendo da eficiência do processo político o bem-estar social aumenta ou diminui. ${ }^{38}$

\section{Interessante é também perceber essa diferenciação em âmbito de EUA, e Europa,}

Tal teoria, entretanto, foi muito presente a partir da década de 1930 nos Estados Unidos com a forte intervenção do Estado no mercado, regulando e fiscalizando, de modo a recuperar a economia e controlar a atuação dos agentes econômicos, tradicionalmente

\footnotetext{
${ }^{37}$ BAGNOLI ,ob. cit. p. 115

${ }^{38}$ BAGNOLI ,ob. cit. p. 116-117
} 
agentes privados. Na Europa, uma forte regulação em defesa do bem público ganha destaque no pós-Segunda Guerra, aplicada aos agentes econômicos privados, mas sobretudo às empresas estatais, os grandes agentes econômicos daquele período. Tal intervenção do Estado, num mercado até então regido simplesmente pela lei da oferta e da procura, teve até mesmo a conotação de uma prática comunista; algo totalmente equivocado. ${ }^{39}$

\section{Contudo passa-se a uma diferenciação entre a regulação e a intervenção direta}

Os objetivos exclusivos da regulação, portanto, acabam agindo como uma intervenção no mercado de forma direta para estruturálo, ainda que condicionando o comportamento dos agentes econômicos, de modo que o mercado funcione e seja um ambiente redistributivo, assegurando o bem-estar social. Já os princípios concorrenciais caracterizam-se como sendo uma intervenção no mercado de forma indireta, por meio da qual os efeitos da aplicação do valor concorrência buscam assegurar o ambiente competitivo, eficiente, no qual pelo acesso à informação consegue-se fazer as melhores escolhas. ${ }^{40}$

\section{Concluindo em três formas de intervenção/regulação}

Já em setores nos quais os serviços podem ser prestados pela iniciativa privada, faz-se necessária a difusão do conhecimento econômico, que assim está sistematizada: (i) due process clause regulação/não intervenção, sendo a regulação a procedimentalização da atividade econômica; desenvolvimento das atividades econômicas em condição de igualdade material entre os agentes econômicos; (ii) regulação institucional - intervenção ativa, com a criação da utilidade pública (concorrência) - (iii) regulação neoclássica: possibilidade de escolha; a concorrência é o valor institucional a ser protegido, e não o mercado. ${ }^{41}$

Percebe-se as várias duvidas em relação a melhor forma de abordar a atividade econômica, seja através de intervenção ou de regulação

Do ponto de vista regulatório, ao realizar um recorte na atuação do CADE nos últimos anos, percebe-se uma carência de uma cultura na área de defesa da concorrência no Brasil, explicada em parte pela reação de setores políticos e empresariais às decisões do CADE (Matias-Pereira, 2004). Para Posner (1998), o funcionamento da economia depende da

\footnotetext{
${ }^{39}$ BAGNOLI ,ob. cit. p. 117

${ }^{40}$ BAGNOLI, ob. cit. p. 119

${ }^{41}$ BAGNOLI ,ob. cit. p. 124
} 
atuação do Estado nas atividades de orientar a concorrência e sancionar condutas ilegítimas.

Sobre o papel de intervenção do estado,

A opção do legislador constituinte, quanto ao sistema econômico a ser instituído no Brasil, foi pelo modelo capitalista de produção, pois se estabeleceu a livre iniciativa como fundamento da Ordem Econômica. No entanto, é nítido o interesse constitucional na redução dos problemas sociais que, na prática do liberalismo estatal puro, restaram demonstrados. Portanto, a economia de mercado, inaugurada em 1988, convive com ditames de justiça social, de modo a valorizar o trabalho humano. Dessa forma, a intervenção estatal sobre o domínio econômico torna-se necessária e, constitucionalmente, legítima para ser exercida não contra o mercado, mas a seu favor, corrigindo distorções e evitando os abusos.

\section{CONCLUSÃO}

No quesito da atividade econômica, objetiva organizar a atividade econômica, porque um reajuste abusivo pelo poder Econômico privado passa a afetar o Direito Fundamental à vida, à saúde e à dignidade da pessoa humana, em busca da Inovação com Desenvolvimento.

A representação entre a tensão da democracia de massas e a concentração do Poder Econômico, tem-se a oportunidade de crescimento do Poder do CADE, como órgão representativo do Poder Estatal indireto e desconcentrado.

Contudo a concepção de Soberania em contraponto ao Constitucionalismo, pode ainda explicar uma limitação prática que o CADE possui nos dias atuais, esse cenário também tem repercussões entre a Intervenção ou a Regulação na Economia, tornando-se uma espécie de política de Estado.

Dessa forma, tem-se a necessidade de criação de instrumentos jurídicos e políticos para controlar o Poder Econômico Privado, no processo de tomada de decisões no âmbito do CADE, para garantia dos Direitos Fundamentais dos Cidadãos, estimulando o eclodir dos sentimentos de Soberania Popular pré-constitucionalismo, trazendo assim maior equilíbrio entre Direito, Economia e Politica, no caminho da Inovação Tecnológica para se alcançar o Desenvolvimento Econômico. 


\section{REFERÊNCIAS BIBLIOGRÁFICAS}

AZEVEDO, Paulo Furquim de. TECNOLOGIA. In: INTRODUÇÃO À ECONOMIA. São Paulo, Atlas, 2007

BAGNOLI, Vicente. Comentários à Nova Lei de Defesa da Concorrência. Método, 2012.

Direito econômico, $6^{\text {a }}$ edição. Atlas, 2013.

e PIERI, Simone. O compliance antitruste.

http://www.valor.com.br/imprimir/noticia/3683748/legislacao/3683748

Introdução à história do direito. Atlas, 2014

BENFATTI, Fábio Fernandes Neves. Direito ao desenvolvimento. São Paulo: Saraiva, 2014.

BERCOVICI, Gilberto. Soberania e Constituição. Para uma critica do Constitucionalismo. Quartier Latin. São Paulo, 2008.

latin.

.. DIREITO ECONOMICO DO PETROLEO E DOS RECURSOS MINERAIS. Quartier

BUCCI, Maria Paula Dallari. Fundamentos para uma Teoria Jurídica das Politicas Publicas, São

Paulo, Saraiva, 2013.

COMPARATO. Fábio Konder Regime Constitucional de Controle de Preços no Mercado. Direito Público, 97/17.

COSTA, R.A.; COSTA, R.M.; AMORIM, G.; BAPTISTA, E.C.S. O impacto da regulação no conservadorismo das empresas brasileiras listadas na BM\&FBOVESPA. Contabilidade, Gestão e Governança, Brasília, v. 12, n. 3, p. 28-37, set-dez, 2009.

DOS SANTOS JUNIOR, Althair Ferreira. Intervenção estatal sobre o domínio econômico: fiscalização, incentivo e planejamento. Revista do Direito Público, v. 3, n. 3, p. 244-264, 2008.

FONSECA, João Bosco. Direito econômico. 5. ed., Rio de Janeiro: Forense, Rio de Janeiro, 2004

FURTADO, Celso. Teoria e política do desenvolvimento econômico. 10. ed. São Paulo: Paz e Terra, 2000 .

GALGANO, Francesco, The New Lex Mercatoria. Annual Survey of International \& Comparative Law: Vol. 2: Iss. 1, Article 7. Available at: http://digitalcommons.law.ggu.edu/annlsurvey/vol2/iss1/7 p. 104.

GRAU, Eros Roberto. A ordem econômica na constituição de 1988. 14. ed. São Paulo: Malheiros, 2010.

O direito posto e o direito pressuposto. 5. São Paulo: Malheiros, 2003. 
GUEDES, K.P.; GASPARINI, C.E. Descentralização fiscal e tamanho do governo no Brasil. Economia Aplicada, São Paulo, v. 11, n. 2, p. 303-323, abril-junho 2007.

Hovenkamp, HERBERT. DISTRIBUTIVE JUSTICE AND CONSUMER WELFARE IN

ANTITRUST, acesso em http://papers.ssrn.com/sol3/papers.cfm?abstract_id=1873463

JULIO, Brandon; YOOK, Youngsuk. Political uncertainty and corporate investment cycles. The Journal of Finance, v. 67, n. 1, p. 45-83, 2012.

LIPSET, Seymour Martin. Some social requisites of democracy: Economic development and political legitimacy. American political science review, v. 53, n. 1, p. 69-105, 1959.

MASSO, Fabiano Dolenc Del. Direito Econômico - Esquematizado. Método, 2012.

MATIAS-PEREIRA, J.. Políticas públicas de defesa do consumidor e da concorrência no Brasil: uma avaliação do processo de consolidação institucional do sistema brasileiro de defesa da concorrência. Revista Académica de Economía,1(24), 1-16. Málaga: Universidad de Málaga, 2004.

MOTTA, A.P.; FUNCHAL, B.; FORTUNATO, G. Os Impactos dos Investimentos no Desempenho das Empresas Brasileiras. XXXIV ENANPAD, Rio de Janeiro, 25 a 29 de setembro de 2010.

OCTAVIANI, Alessandro. RECURSOS GENETICOS E DESENVOLVIMENTO: OS DESAFIOS FURTADIANO E GRAMSCIANO. Editora Saraiva, 2013.

OLIVEIRA, Francisco de, A Economia Brasileira: Crítica à Razão Dualista e O Ornitorrinco, São Paulo, Boitempo, 2003

POSNER, Richard A. Economic analysis of law. Wolters Kluwer Law \& Business, 2014.

POSSAS, Silvia, Concorrencia e Inovação, in ECONOMIA DA INOVAÇÃO TECNOLOGIA, Editora HUCITEC, Ordem dos Economistas do Brasil, São Paulo, 2006

STRECK, Lênio Luiz, Jurisdição constitucional e hermenêutica: uma nova crítica do direito. 2. ed., revista e ampliada. Rio de Janeiro: Forense, 2004.

Hermenêutica Jurídica e(m) crise: uma exploração hermenêutica da construção do Direito. 5. ed., revista, atualizada. Porto Alegre: Livraria do Advogado, 2004. 